\title{
Preventing falls among older people with mental health problems: a systematic review
}

Frances Bunn ${ }^{1 *}$, Angela Dickinson ${ }^{1}$, Charles Simpson ${ }^{1}$, Venkat Narayanan ${ }^{2}$, Deborah Humphrey ${ }^{2}$, Caroline Griffiths², Wendy Martin ${ }^{3}$ and Christina Victor ${ }^{3}$

\begin{abstract}
Background: Falls are a leading cause of mortality and morbidity in older people and the risk of falling is exacerbated by mental health conditions. Existing reviews have focused on people with dementia and cognitive impairment, but not those with other mental health conditions or in mental health settings. The objective of this review is to evaluate the effectiveness of fall prevention interventions for older people with mental health problems being cared for across all settings.
\end{abstract}

Methods: A systematic review of fall prevention interventions for older people with mental health conditions. We undertook electronic database and lateral searches to identify studies reporting data on falls or fall related injuries. Searches were initially conducted in February 2011 and updated in November 2012 and October 2013; no date restrictions were applied. Studies were assessed for risk of bias. Due to heterogeneity results were not pooled but are reported narratively.

Results: Seventeen RCTs and four uncontrolled studies met the inclusion criteria; 11 involved single interventions and ten multifactorial. Evidence relating to fall reduction was inconsistent. Eight of 14 studies found a reduction in fallers (statistically significant in five), and nine of 14 reported a significant reduction in rate or number of falls. Four studies found a non-significant increase in falls. Multifactorial, multi-disciplinary interventions and those involving exercise, medication review and increasing staff awareness appear to reduce the risk of falls but evidence is mixed and study quality varied. Changes to the environment such as increased supervision or sensory stimulation to reduce agitation may be promising for people with dementia but further evaluation is needed. Most of the studies were undertaken in nursing and residential homes, and none in mental health hospital settings.

Conclusions: There is a dearth of falls research in mental health settings or which focus on patients with mental health problems despite the high number of falls experienced by this population group. This review highlights the lack of robust evidence to support practitioners to implement practices that prevent people with mental health problems from falling.

Keywords: Systematic review, Falls, Older people, Mental health

\section{Background}

Falls are the most commonly reported patient-safety incident in mental health settings for older people [1] with approximately 36,000 falls reported in these settings annually in England alone [2]. Similar numbers of falls and injuries in mental health settings are also reported in other countries e.g. Australia [3] and the United States [4].

\footnotetext{
* Correspondence: f.bunn@herts.ac.uk

${ }^{1}$ Centre for Research in Primary and Community Care, University of Hertfordshire, Hatfield, Hertfordshire AL10 9AB, UK

Full list of author information is available at the end of the article
}

Risk of falling is exacerbated by mental health problems, such as impaired mental status due to dementia [5], depression [6] mania and anxiety [7]. In addition, treatments of mental health conditions, for example, with psychotropic medication [8,9] and electroconvulsive therapy [10] also increase fall risk. Falls affect rehabilitation, physical and mental function, can increase length of stay in hospital settings and the likelihood of discharge to long-term care settings [11]. Health care costs associated with falls are increasing worldwide [12], with falls in older people with

\section{Biomed Central}

(c) 2014 Bunn et al.; licensee BioMed Central Ltd. This is an Open Access article distributed under the terms of the Creative Commons Attribution License (http://creativecommons.org/licenses/by/2.0), which permits unrestricted use, distribution, and reproduction in any medium, provided the original work is properly credited. 
mental health conditions associated with greater costs compared to the general population of older people [4].

A previous systematic review [13] investigated the effects of cognitive impairment, in particular dementia, on strategies to prevent falls and fractures in hospitals and care homes, and included studies that had been undertaken in a range of settings including Accident and Emergency, care homes, acute general hospitals, sub-acute units and rehabilitation wards. However, no studies were reported from mental health settings, and the authors did not explore mental health conditions other than dementia and cognitive impairment. A more recent review [14] also focused on Alzheimer's disease and related dementias. Although other reviews have looked at fall prevention in hosptial settings $[15,16]$ we did not find any systematic reviews which explored fall prevention interventions specifically in mental health settings or which focused on people with mental health problems. The evidence-base for fall prevention interventions for older people with mental health problems appears to be poorly developed $[17,18]$. A lack of clear evidence leaves practitioners, particularly nurses who provide the day-to-day care of patients, to struggle to prevent and manage falls in these populations [19].

This paper presents the results of a systematic review where we addressed the following aim: What interventions are effective in preventing and managing falls among older people with mental health conditions.

\section{Methods}

The systematic review was carried out using methodology employed by the review team in previous reviews, and in accordance with that recommended by the Cochrane Collaboration [20]. The inclusion criteria and methods for the review were pre-specified in a protocol (available on request from authors).

\section{Search strategy and selection criteria}

We searched for published and unpublished English language studies that evaluated an intervention aimed at preventing or reducing falls in older people with a mental health problem, regardless of setting. Studies were identified from searching a range of electronic databases including Pubmed, NHS evidence, Cochrane Library inc, Cochrane Database of Systematic Reviews, Database of Abstracts of Reviews of Effects, CENTRAL, NHS Economic Evaluation Database and the Health Technology Assessment Database, Cinahl, AMED, BNI, Embase, HMIC, PsychInfo; and by using lateral search techniques such as checking reference lists, and using the 'Cited by' option on Web Of Science (WoS) and Google Scholar, and the 'Related articles' option on PubMed and WoS. Searches were first conducted in February 2011 and updated in November 2012 with lateral searching ongoing until October 2013; no date restrictions were applied. Further details of the search terms used can be seen in Table 1.

We included both randomised controlled trials and controlled evaluations of fall prevention interventions for people aged 60 and over with any mental health problem including dementia, depression or psychosis. Studies that did not have a specific mental health focus were included as long as a significant percentage (e.g. $50 \%$ or more) of participants had a mental health problem, or data was reported separately for those with a mental health condition. As preliminary searches suggested there was a lack of controlled studies we included uncontrolled studies, but only if all participants had a mental health problem. We included single focus or multi-factorial interventions involving environmental, exercise, technological, psychological, educational, and health related components. Our primary interest was in studies delivered in in-patient mental health settings but interventions delivered in other settings were included as long as the study included older people with a mental health problem. The primary outcomes of interest were the number of participants sustaining at least one fall (fallers) and data relating to the rate or number of falls. Secondary outcomes included fall related injuries, hip fractures, service use and patient satisfaction. In addition, we searched for qualitative studies or process evaluations that identified barriers and facilitators to the implementation and uptake of interventions; in particular looking at whether specific guidance is required for this group.

\section{Data extraction and critical appraisal}

Two reviewers independently screened titles and abstracts of citations identified by electronic searches, applied the selection criteria to potentially relevant papers and extracted data from included studies using a standardised form which was piloted prior to use. Any disagreements were resolved by consensus or by discussion with a third reviewer. We extracted information on the type of study design, study aims, participants, setting, intervention (including details of provider, duration and intensity) and outcomes.

Two reviewers independently assessed the quality of included studies. RCTs and controlled studies were assessed using the Cochrane Collaboration risk of bias tool [20], and uncontrolled studies were assessed on domains adapted from two check lists [21,22]. Full details of the quality domains can be seen in Table 2 .

\section{Analysis}

The interventions in the included studies were classified using the fall prevention classification system developed by the Prevention of Falls Network Europe (ProFANE) [23]. This groups studies by setting (nursing/residential care, hospital, community), by combination (single, multifactorial) 
Table 1 Example of search terms

\author{
Database \& date searched
}

PubMed (February 2011)

\section{Search terms}

fall*[ti] AND (falls OR accidental falls OR falls in the elderly) AND (mental disorders OR mental

health OR dementia OR cognitive impairment OR cognitive disorder OR depression OR paranoia OR personality disorder OR anxiety OR delerium OR amnesia OR parkinsons)

* $=$ Truncatated.

and by type of intervention including exercise, social environment, environment/assistive technology, knowledge, and other (multi-sensory stimulation). Populations were not homogenous and the Chi-Square test and $\mathrm{I}^{2}$ test [24] revealed significant heterogeneity and thus studies were not pooled in a meta-analysis. Instead we have presented data in the text and in a table with an indication of whether the effect of the intervention was positive, negative or not statistically significant. Where possible we have reported dichotomous outcomes as relative risks or incidence rate ratios and continuous data as mean differences, both with 95\% confidence intervals. Where data were not available to allow us to calculate effect sizes we have presented data as reported in the paper (for example P values).

\section{Results}

\section{Selected studies}

We identified 4614 studies from our electronic and lateral searches of which 27 papers [25-51] reporting 21 studies

Table 2 Quality assessment criteria by study type

\begin{tabular}{|c|c|}
\hline \multicolumn{2}{|c|}{ Randomised controlled trials all scored as Yes $(+) /$ No $(-) /$ Unclear } \\
\hline Sequence generation & $\begin{array}{l}\text { Was the allocation sequence adequately } \\
\text { generated? }\end{array}$ \\
\hline Allocation concealment & Was allocation adequately concealed? \\
\hline Blinding & $\begin{array}{l}\text { Was knowledge of the allocation intervention } \\
\text { adequately concealed from outcome assessors? }\end{array}$ \\
\hline $\begin{array}{l}\text { Incomplete } \\
\text { outcome data- }\end{array}$ & Was this adequately addressed for each outcome? \\
\hline $\begin{array}{l}\text { Selective outcome } \\
\text { reporting }\end{array}$ & $\begin{array}{l}\text { Are reports of the study free of suggestion of } \\
\text { selective outcome reporting? }\end{array}$ \\
\hline Other source of bias & $\begin{array}{l}\text { Was the study apparently free of other problems } \\
\text { that could put it at a high risk of bias? }\end{array}$ \\
\hline \multicolumn{2}{|c|}{ Uncontrolled before after studies all scored as Yes $(+) /$ No $(-) /$ Unclear } \\
\hline Selection bias & $\begin{array}{l}\text { Are the individuals selected to participate in } \\
\text { the study likely to be representative of the } \\
\text { target population? }\end{array}$ \\
\hline Blinding & $\begin{array}{l}\text { Was knowledge of the allocation intervention } \\
\text { adequately concealed from outcome assessors? }\end{array}$ \\
\hline Detection bias & $\begin{array}{l}\text { Outcomes reported and measured in } \\
\text { standardised way }\end{array}$ \\
\hline $\begin{array}{l}\text { Incomplete } \\
\text { outcome data }\end{array}$ & Was this adequately addressed for each outcome? \\
\hline $\begin{array}{l}\text { Selective outcome } \\
\text { reporting }\end{array}$ & $\begin{array}{l}\text { Are reports of the study free of suggestion of } \\
\text { selective outcome reporting? }\end{array}$ \\
\hline Other source of bias & $\begin{array}{l}\text { Was the study apparently free of other problems } \\
\text { that could put it at a high risk of bias? }\end{array}$ \\
\hline
\end{tabular}

met the inclusion criteria. Studies were published between 1997 and 2013, with all but one published in the last ten years. Seventeen studies were randomised, with eight being cluster RCTs [26,27,33,34,39,41-43], and nine with randomisation at the level of the individual $[28,32,36,38,44,45,48,50,51]$. Four studies were uncontrolled $[29,30,37,46]$. Length of follow up ranged from 3 to 12 months. We found no qualitative studies or process evaluations. A flow chart detailing the identification of studies can be seen in Figure 1.

\section{Setting and populations}

Nine studies were conducted in Europe, five in Australia, five in North America and two in Japan. Fourteen studies took place in nursing homes or residential care [26-30,34,36,39,41-43,45,46], or included participants who mostly resided in nursing or residential care [52], three took place in hospital $[33,38,48]$, one in a respite day centre [37], one a geriatric outpatient clinic [32] and two in participants' own homes [44,51]. In ten studies participants all (or most) had dementia or cognitive impairment [27-30,36-39,45,51,52], four studies reported sub-group analyses for participants with cognitive impairment $[33,35,41]$ or depression [44] and the rest included $48 \%$ or over of people with mental health problems (largely dementia).

\section{Intervention characteristics}

Ten studies involved multi-factorial interventions [32,34,37,39,41,42,44,47,48,51]; and included components such as staff training, physical activity or training and environmental assessment. Of the single component interventions two focused on knowledge based interventions [26,33], five on the environment $[27,29,30,38,46]$ two on physical activity or exercise [28,43], and two on sensory stimulation, one involving, olfactory stimulation with lavender oil [45], and the other multisensory stimulation through a Snoezelen room [36]. ProFANE classifications can be seen in Table 3 and further details of included studies (including the links between papers) in Table 4 .

\section{Outcomes}

All 21 included studies reported falls data in some form, although seven did not include a specific definition of a fall $[27,28,30,36-38,46]$. In the others a fall was defined as unintentionally [34,41-44,48,51], inadvertently [33,39,45,47], or unexpectedly [32] coming to rest on the ground, floor, or a 
Records identified through initial database searching $(n=4236)$

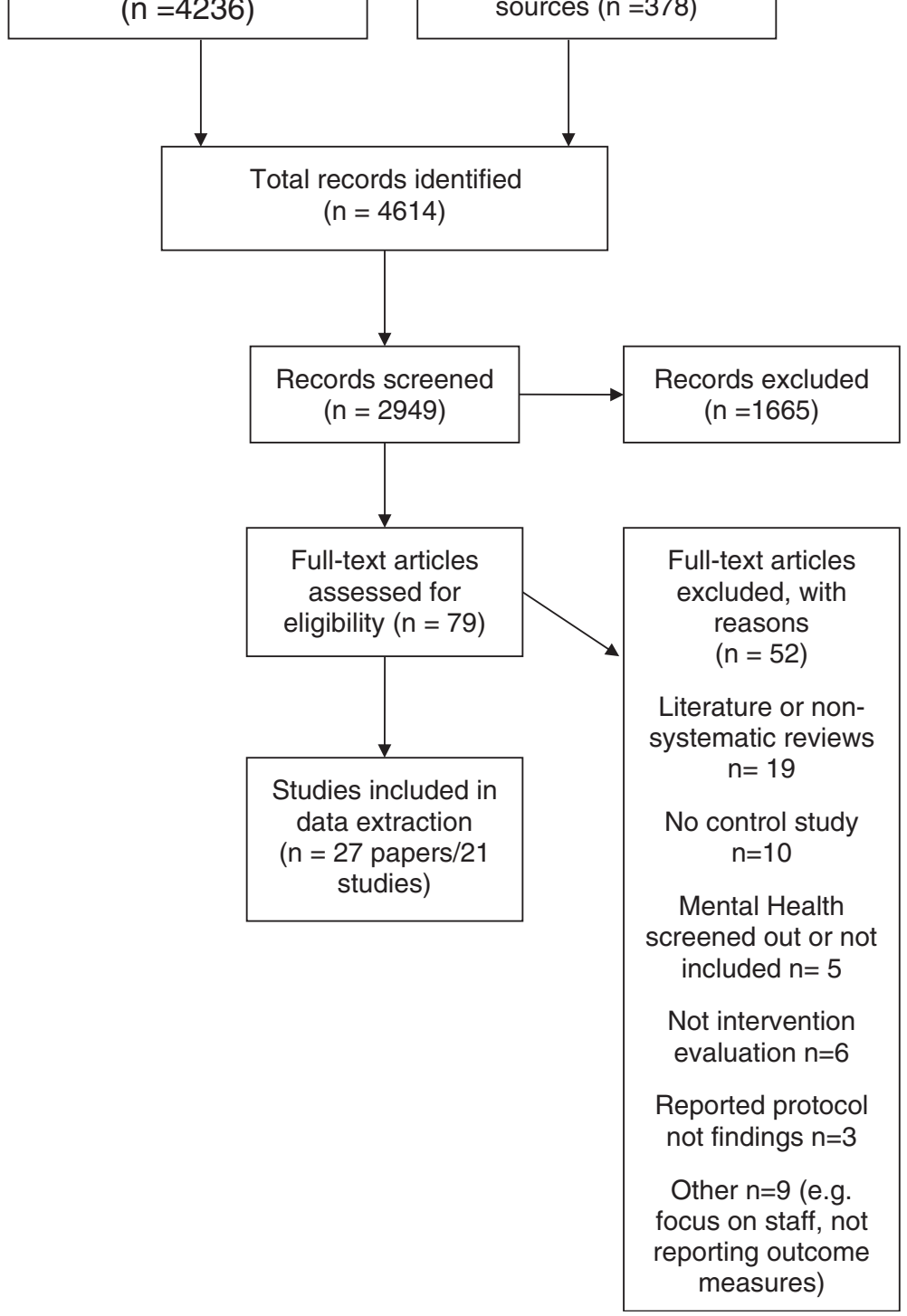

Additional records identified through other sources $(n=378)$

Figure 1 Flow chart of study selection process.

lower level; whether or not an injury was sustained $[34,43,44,47]$. One study included syncopal falls [48], one both witnessed and non-witnessed falls [29]; one only took account of falls where medical intervention was needed [26], and one categorised injurious falls as those resulting in serious injuries that received medical treatment [42].

\section{Risk of bias}

Results of the risk of bias assessment can be seen in Figure 2 (RCTs) and Figure 3 (uncontrolled studies). Of the 17 randomised controlled studies sequence generation was considered adequate in thirteen studies, as was allocation concealment. However, only ten studies were judged to have both adequate sequence generation and allocation concealment $[27,33,36,38,41,44,45,47,48,51]$. Four studies $[33,45,47,48]$ met all quality criteria and six met five or more of the six quality criteria [32,41,43,44,47,51]. One RCT [28] met none of the criteria. Of the four uncontrolled studies three met three out of six of the criteria $[29,37,46]$ and one met two out of six [30], but all are at high risk of bias because they have no control group.

\section{Evidence of effectiveness}

Results are presented by setting and according to whether the intervention was single or multifactorial. A summary 
Table 3 Overview of setting and intervention type using PROFANE domains

\begin{tabular}{|c|c|c|c|c|c|c|c|c|c|}
\hline Setting/combination & Study ID & Exercise & Medications & $\begin{array}{l}\text { Management } \\
\text { of urinary } \\
\text { incontinence }\end{array}$ & $\begin{array}{l}\text { Fluid/ } \\
\text { nutrition } \\
\text { therapy }\end{array}$ & $\begin{array}{l}\text { Environment/ } \\
\text { assistive } \\
\text { technology }\end{array}$ & $\begin{array}{l}\text { Social } \\
\text { environment }\end{array}$ & Knowledge & Other \\
\hline \multicolumn{10}{|l|}{$\begin{array}{l}\text { Nursing/residential } \\
\text { care facility }\end{array}$} \\
\hline \multirow[t]{9}{*}{ Single } & $\begin{array}{l}\text { Bouwen } \\
2008[26]\end{array}$ & & & & & & & $* * * *$ & \\
\hline & $\begin{array}{l}\text { Buettner } \\
2002[28]\end{array}$ & $* * * *$ & & & & & & & \\
\hline & $\begin{array}{l}\text { Chenowith } \\
2009 \text { [27] }\end{array}$ & & & & & & $* * * *$ & & \\
\hline & $\begin{array}{l}\text { Detweiler } \\
2005 \text { [29] }\end{array}$ & & & & & & $* * * *$ & & \\
\hline & $\begin{array}{l}\text { Detweiler } \\
2009 \text { [30] }\end{array}$ & & & & & $* * * *$ & & & \\
\hline & $\begin{array}{l}\text { Klages } \\
2011[36]\end{array}$ & & & & & & & & $\begin{array}{l}\text { *****Multisenson } \\
\text { stimulation }\end{array}$ \\
\hline & $\begin{array}{l}\text { Rosendahl } \\
2008 \text { [43] }\end{array}$ & $* * * *$ & & & & & & & \\
\hline & $\begin{array}{l}\text { Sakamoto } \\
2012[44]\end{array}$ & & & & & & & & $\begin{array}{l}* * * \text { Lavender } \\
\text { patches }\end{array}$ \\
\hline & $\begin{array}{l}\text { Shimada } \\
2009[45]\end{array}$ & & & & & & $* * * *$ & & \\
\hline \multicolumn{10}{|l|}{ Multifactorial } \\
\hline & $\begin{array}{l}\text { Jenson } \\
2003[35]\end{array}$ & $* * * *$ & $* * * *$ & & & $* * * *$ & $* * * *$ & & \\
\hline & $\begin{array}{l}\text { Neyens } \\
2009[40]\end{array}$ & $* * * *$ & $* * * *$ & & & $* * * *$ & $* * * *$ & & \\
\hline & $\begin{array}{l}\text { Rapp } \\
2008 \text { [41] }\end{array}$ & $* * * *$ & & & & & & $* * * *$ & \\
\hline & Ray 1997 [42] & & $* * * *$ & & & $* * * *$ & $* * * *$ & $* * * *$ & \\
\hline & $\begin{array}{l}\text { Shaw } \\
2003[46]\end{array}$ & $* * * *$ & $* * * *$ & & & $* * * *$ & & & \\
\hline \multicolumn{10}{|l|}{ Hospital } \\
\hline \multirow[t]{2}{*}{ Single } & $\begin{array}{l}\text { Haines } \\
2011[33]\end{array}$ & & & & & & & $* * * *$ & \\
\hline & $\begin{array}{l}\text { Mador } \\
2004[38]\end{array}$ & & & & & & $* * * *$ & & \\
\hline Multifactorial & $\begin{array}{l}\text { Stenvall } \\
2007[47]\end{array}$ & & $* * * *$ & $* * * *$ & $* * * *$ & $* * * *$ & $* * * *$ & & \\
\hline \multicolumn{10}{|l|}{ Community based } \\
\hline \multirow[t]{4}{*}{ Multifactorial } & Faes 2011 [32] & $* * * *$ & & & & & & $* * * *$ & \\
\hline & $\begin{array}{l}\text { Mackintosh } \\
2005[37]\end{array}$ & $* * * *$ & & & & $* * * *$ & & & \\
\hline & $\begin{array}{l}\text { Wesson } \\
2013[51]\end{array}$ & $* * * *$ & & & & & & $* * * *$ & \\
\hline & $\begin{array}{l}\text { Salminen } \\
2009[43]\end{array}$ & $* * * *$ & $* * * *$ & & & $* * * *$ & & $* * * *$ & \\
\hline
\end{tabular}

\footnotetext{
****Intervention type.
}

of the data, including effect sizes, can be seen in Table 5 . Study quality is reported in the text for those studies judged to be at low or high risk of bias; all quality scores can be seen in Table 5.
Nursing/residential care: single interventions

Two studies looked at exercise programmes in nursing or residential care. One [28] (high risk of bias) found a significant reduction in numbers of fallers and the other 
Table 4 Summary of included studies characterised using PROFANE domains

\begin{tabular}{|c|c|c|}
\hline & $\begin{array}{l}\text { Authors and } \\
\text { study design }\end{array}$ & Research question \\
\hline $\begin{array}{l}\text { Single } \\
\text { interventions }\end{array}$ & & \\
\hline
\end{tabular}

\section{Exercise}

Buettner 2002 [28]

RCT (2 months FU)

Rosendahl et al. 2008 [43]

Cluster RCT

(6 months FU)

Environment/

assistive

technology

Detweiler et al. 2009 [30] (also Detweiler 2008) [31]

Uncontrolled before/after study

(12 months FU)

\section{Social} environment

Detweiler et al. 2005 [29]

Uncontrolled before/after study (4 month FU)

Shimada et al. 2009 [45]

Uncontrolled before/after study (25 week FU)

Chenowith et al. 2009 [27]

Cluster RCT (4 Month FU)

Mador et al. 2004 [38]
Description of intervention

Setting

\section{Participants}

(n)

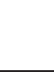



Does a therapeutic recreation intervention reduce falls in older adults with dementia?

I = 3 month therapeutic recreation program delivered at time of day and location where falls occurred; to increase strength, endurance, flexibility and balance.

$\mathrm{C}=$ usual activities

Does an exercise program $\quad$ I= 3 month individualised reduce falls in residential weight-bearing exercise care facilities? intervention

$\mathrm{C}=$ non-exercise control activity while sitting

Does a dementia wander garden and medication review reduce number and severity of falls?

I = wander garden and medication review

Does consistent supervision during day and evening shifts reduce falls in dementipea unit?

Does a falls prevention aide using systematic supervision reduce falls?

Investigate effectiveness of person-centred care and dementia-care mapping compared with each other and with conventional dementia care

Does individualized advice on nonpharmacological strategies for hospitalized older patients with confusion and behavioural problems improve levels of agitation and reduce the use of psychotropic medication.
25 people with dementia \& history of previous falls. Aged 60+ (mean age 83), MMSE $<=23(\mathrm{M}=2.63)$

191 people aged 65+ (mean age 85), MMSE 10+ $(M=17.8), 52 \%$ with dementia

28 people with dementia aged 74-92 (mean age 81).
Nursing Home, America

Residential Care, Sweden

Residential Dementia Care unit, America
I = Aide delivered intervention, targeting residents considered to be at high risk of falls

= Supervision focusing on behavioural and environmental factors.

8 older people with dementia aged 74 to 85 (mean age 81)

60 people aged 68-105 (mean age 87), 48\% Dementia, $5 \%$ cognitive impairment , $2 \%$ depression

| 1= Person centred care

1 2= Dementia care mapping.

$\mathrm{C}=$ Usual care.

I= Patient assessment, non-pharmacological management plan, on-going support and education for nursing staff. Tailored to patient needs-included addressing patient safety, minimising restraint use, reducing fall risk, communication, behavioural strategies and education.
296 Average age: 83 for dementia care mapping 84 for person centred care 85 usual care

71 older people with confusion
Dementia Care Home, America
Long-term aged-care facility, Japan.

Residential Care sites, Australia

Acute Hospital, Australia 
Table 4 Summary of included studies characterised using PROFANE domains (Continued)

\begin{tabular}{|c|c|c|c|c|c|}
\hline & $\begin{array}{l}\text { RCT (FU to } \\
\text { discharge) }\end{array}$ & & $\begin{array}{l}\mathrm{C}=\text { usual care- included } \\
\text { review with geriatrican. }\end{array}$ & Mean age $\quad I=82, C=83$ & \\
\hline \multicolumn{6}{|l|}{ Knowledge } \\
\hline & $\begin{array}{l}\text { Bouwen et al. } \\
2008[26]\end{array}$ & $\begin{array}{l}\text { Does a staff-oriented } \\
\text { intervention impact on } \\
\text { the number of accidental } \\
\text { falls in residents with and } \\
\text { without cognitive } \\
\text { impairment? }\end{array}$ & $\begin{array}{l}\text { I = } 6 \text { wk multifaceted } \\
\text { intervention involving } \\
\text { staff training on falls } \\
\text { risk factors, followed by } \\
\text { a falls diary and patient } \\
\text { questionnaire linking risk } \\
\text { with possible interventions. }\end{array}$ & $\begin{array}{l}379 \text { older people with } \\
\text { mean age of } 83 \text { and MMSE } \\
<23(M=15.72)\end{array}$ & $\begin{array}{l}\text { Nursing Home, } \\
\text { Belgium }\end{array}$ \\
\hline & $\begin{array}{l}\text { Cluster RCT } \\
(6 \text { month FU) }\end{array}$ & & $\begin{array}{l}\mathrm{C}=\text { no staff training, no } \\
\text { diary, no questionnaire }\end{array}$ & & \\
\hline & $\begin{array}{l}\text { Haines et al. } \\
2011 \text { [33] }\end{array}$ & $\begin{array}{l}\text { Evaluative comparison } \\
\text { of } 2 \text { forms of multimedia } \\
\text { patient education } \\
\text { intervention alongside } \\
\text { usual care for the } \\
\text { prevention of falls. }\end{array}$ & $\begin{array}{l}\text { I1 = written and video } \\
\text { based intervention materials } \\
\text { and 1-to- } 1 \text { follow-up with a } \\
\text { physiotherapist, in addition } \\
\text { to usual ward based care } \\
\text { (median time spent with } \\
\text { patient } 25 \text { (20-36) minutes, } \\
\text { maximum with one patient } \\
200 \text { minutes). }\end{array}$ & $\begin{array}{l}1206 \text { people aged } 60+ \\
\text { (mean age } 75), \text { mean } \\
\text { SPMSQ }=8.4,25 \% \text { cognitive } \\
\text { impairment }\end{array}$ & In-patient, Australia \\
\hline & $\begin{array}{l}\text { Cluster RCT } \\
\text { (FU to discharge) }\end{array}$ & & $\begin{array}{l}12 \text { = intervention materials } \\
\text { provided but without 1-to-1 } \\
\text { with physiotherapist, in } \\
\text { addition to usual ward } \\
\text { based care. }\end{array}$ & & \\
\hline & & & $\mathrm{C}=$ usual ward based care & & \\
\hline \multicolumn{6}{|l|}{ Other } \\
\hline \multirow[t]{2}{*}{$\begin{array}{l}\text { Multisensory } \\
\text { stimulation }\end{array}$} & $\begin{array}{l}\text { Klages et al. } \\
2011[36]\end{array}$ & \multirow{2}{*}{$\begin{array}{l}\text { To investigate the } \\
\text { influence of multisensory } \\
\text { stimulations in a Snoezelen } \\
\text { room on the balance of } \\
\text { individuals with dementia. }\end{array}$} & $\begin{array}{l}\text { I= } 30 \text { mins use of a Snoezelen } \\
\text { room twice a week for } 6 \\
\text { weeks. }\end{array}$ & $\begin{array}{l}19 \text { older people, mean age } \\
86 . \text { MMSE } 12 \text { (range } 4-22) \\
\text { for IV group, } 13 \text { (2-22) for }\end{array}$ & \multirow[t]{2}{*}{$\begin{array}{l}\text { Long term care } \\
\text { home, Canada }\end{array}$} \\
\hline & $\begin{array}{l}\text { RCT (FU } 6 \text { weeks } \\
\text { post intervention) }\end{array}$ & & $\begin{array}{l}\text { C= volunteer spending } \\
\text { same amount of time } \\
\text { 1-to-1 with resident. }\end{array}$ & $\begin{array}{l}\text { control. Able to walk with } \\
\text { minimal assistance and } \\
\text { understand simple instructions. }\end{array}$ & \\
\hline \multirow[t]{2}{*}{$\begin{array}{l}\text { Multisensory } \\
\text { stimulation }\end{array}$} & $\begin{array}{l}\text { Sakamoto et al. } \\
2012[44]\end{array}$ & \multirow[t]{2}{*}{$\begin{array}{l}\text { Does a lavender olfactory } \\
\text { stimulation intervention } \\
\text { reduce falls in nursing } \\
\text { home residents? }\end{array}$} & $\begin{array}{l}\text { I = } 12 \text { month, } 24 \text { hour } \\
\text { exposure to lavender } \\
\text { olfactory stimulation patch } \\
\text { on clothes near neck }\end{array}$ & $\begin{array}{l}145 \text { people aged } 65+ \\
\text { (mean age } 84 \text { ), mean } \\
\text { MMSE }=15 . \text { able to transfer } \\
\text { independently }\end{array}$ & \multirow[t]{2}{*}{ Nursing Home, Japan } \\
\hline & $\mathrm{RCT}$ (360 days FU) & & $\begin{array}{l}\mathrm{C}=\text { same patch and } \\
\text { duration as intervention, } \\
\text { but no lavender }\end{array}$ & & \\
\hline \multicolumn{6}{|c|}{$\begin{array}{l}\text { B: Combination interventions: } \\
\text { multiple }\end{array}$} \\
\hline & Wesson 2013 [51] & $\begin{array}{l}\text { To test design and } \\
\text { feasibility of a home } \\
\text { hazard reduction and } \\
\text { balance and strength } \\
\text { exercise fall prevention } \\
\text { program for people } \\
\text { with mild dementia } \\
\text { living in the community. }\end{array}$ & $\begin{array}{l}\text { I= Strength \& balance } \\
\text { training, home hazard } \\
\text { reduction, discussion of } \\
\text { behaviour and management } \\
\text { issues with carers. Carers } \\
\text { supervised exercise } \\
\text { and responsible for } \\
\text { implementation of home } \\
\text { safety recommendations. }\end{array}$ & 11 patient and carer dyads. & Community, Australia \\
\hline & \multirow[t]{2}{*}{$\mathrm{RCT}$ (4 month FU) } & & $C=$ Usual care. & \multirow[t]{2}{*}{ Mean age $I=78.7, C=80.9$} & \\
\hline & & & $\begin{array}{l}\text { Both groups received } \\
\text { health promotion } \\
\text { brochures on fall } \\
\text { prevention and home } \\
\text { safety. }\end{array}$ & & \\
\hline
\end{tabular}


Table 4 Summary of included studies characterised using PROFANE domains (Continued)

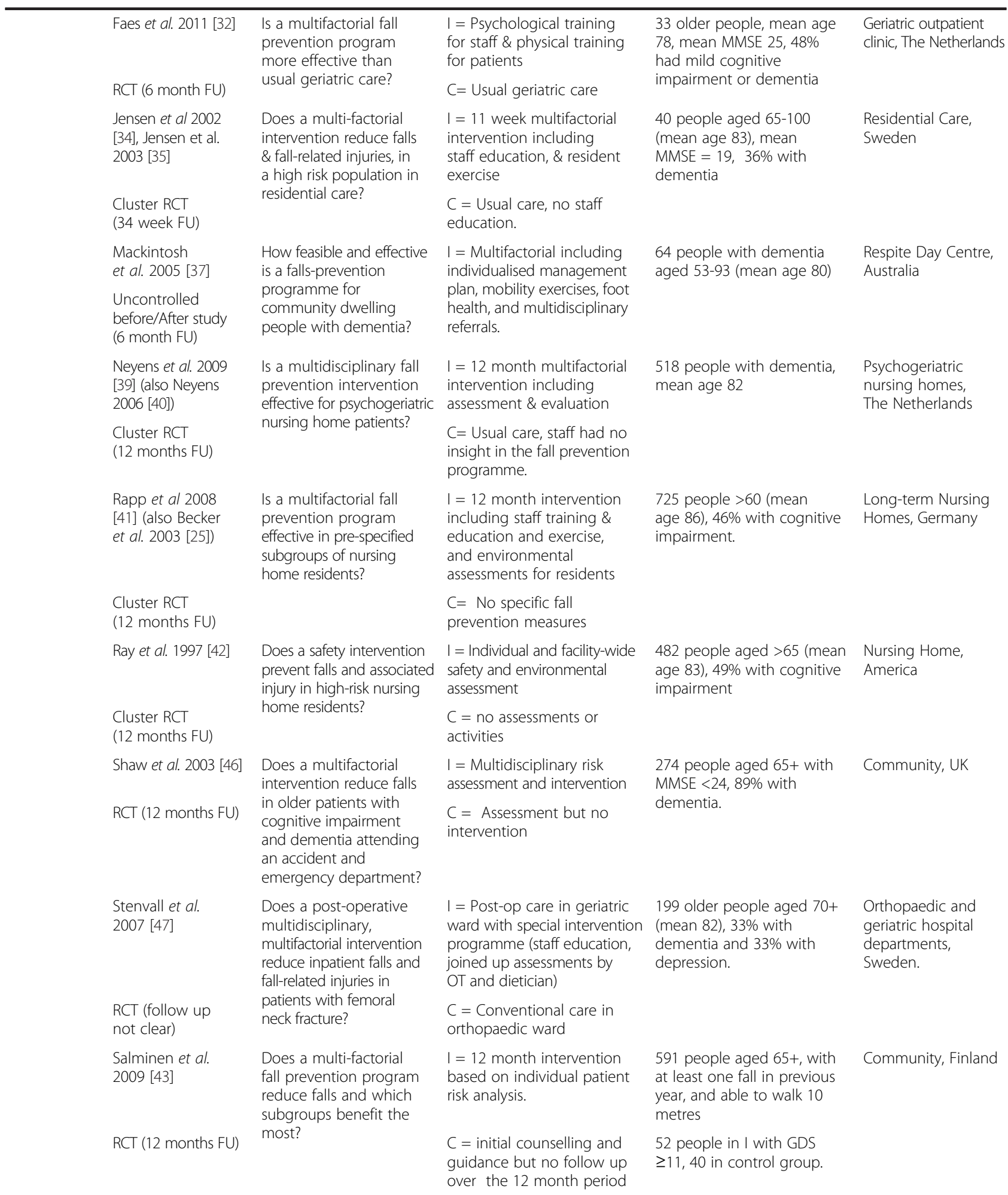

I, intervention; $C$, control; $M$, mean; MMSE, mini mental state examination.

(low risk of bias) [43] no difference in number of fallers but a non-significant reduction in rate of falls and hip fractures. Four studies looked at some form of environmental intervention. One, a study of a wander garden found a significant reduction in the mean number of falls [30] but this was an uncontrolled study and at high risk of 


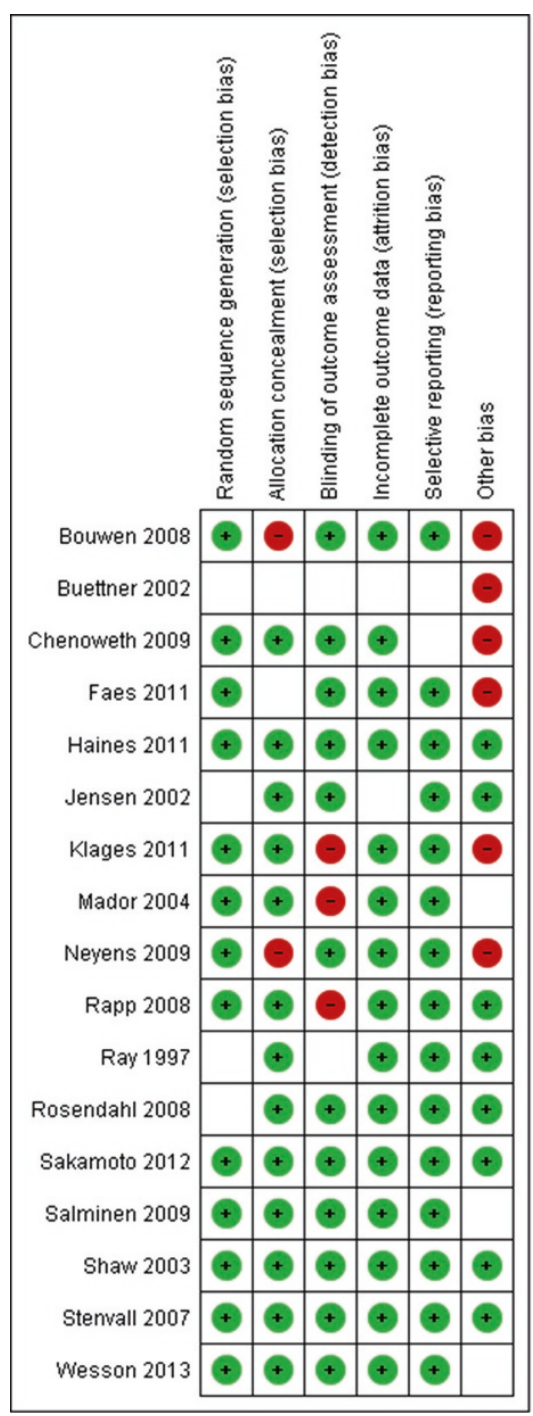

$+=$ Low risk of bias
$-=$ High risk of bias
Blank = Unclear risk of bias

Figure 2 Risk of bias summary: review authors' judgements about risk of bias item for each included study (RCTs).

bias. Of the other social environmental interventions two studies involving increased supervision $[29,46]$ reported a significant reduction in number of fallers, but both were at high risk of bias. A study comparing dementia care mapping (DCM), person-centred care (PCC) and usual care found a reduction in falls in the DCM group compared to control but an increase in the PCC group compared to control [27]. One study which involved a knowledge based intervention for staff reported a significant reduction in fallers but no difference in the rate of falls [26]. Two studies evaluated a sensory intervention. One study of lavender patches (low risk of bias) found a non-significant reduction in number of fallers and a significant reduction in incidence of falls [45] and a study of multisensory stimulation in a Snoezelen room found no difference in the number of falls in the intervention group compared to control [36].

\section{Nursing/residential care: multifactorial interventions}

Five studies looked at multifactorial interventions in nursing homes or residential care. Common components of these interventions were exercise, medication management, changes to the environment and activities to improve staff knowledge. Two studies report a significant reduction in the rate of falls $[40,41]$ in participants with cognitive impairment. However, in the latter there was a non-significant increase in the number of hip fractures in the intervention group compared to control. One low risk of bias study found a slight (non-significant) reduction in fallers but a non-significant increase in fall related $A \& E$ admissions [52], and one a non-significant reduction in injurious falls and number of recurrent fallers [42]. One study which undertook subgroup analyses for participants with cognitive impairment found that the intervention significantly reduced the number of fallers in those with 


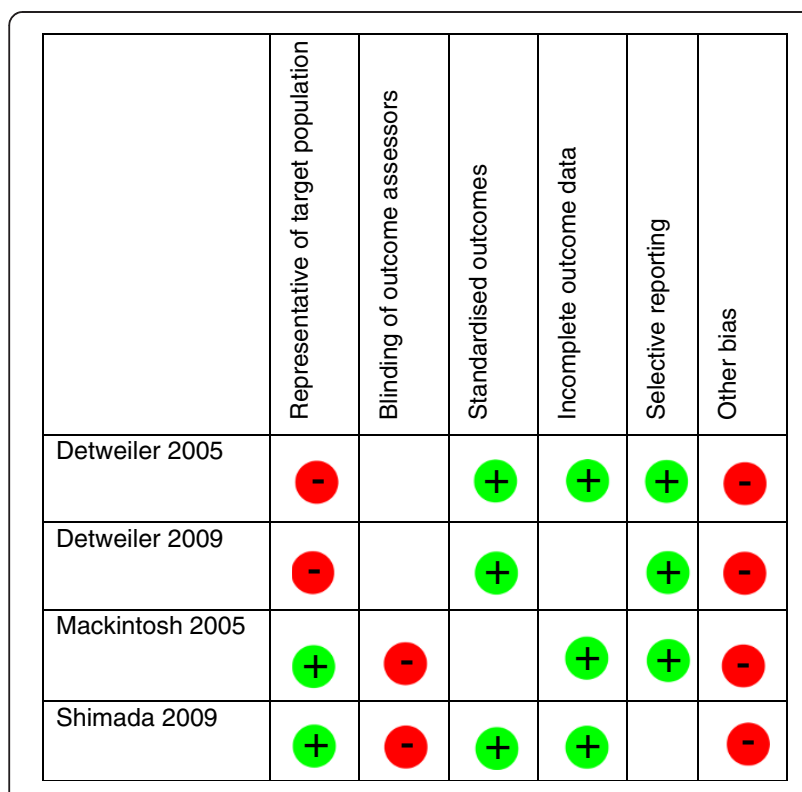

Figure 3 Risk of bias summary: review authors' judgements about risk of bias item for each included study (Uncontrolled studies).

no cognitive impairment but not in the group with cognitive impairment [35].

\section{Hospital: single interventions}

Neither of the hospital based studies found a reduction in falls in those with cognitive impairment. A study of multimedia patient education (low risk of bias) compared multi-media education with health professional follow-up, multi-media materials alone and usual care [33]. Although the complete intervention reduced falls amongst participants who were cognitively intact this was not the case for those with cognitive impairment. Amongst those with cognitive impairment there was an increase in the number of fallers, fall incidence and injurious falls in the group that received the complete intervention but no difference in fallers or fall rate in the group that received materials only. The other hospital based RCT evaluated the impact of nurse led individualised advice to staff aiming to reduce agitation and the use of psychotropic medication in patients with confusion and behavioural problems. They found a non-significant increase in falls in the intervention group compared to control [38].

\section{Hospital: multifactorial interventions}

There was one (low risk of bias) multifactorial hospital based intervention [48]. They found a significant reduction in fallers and in fall incidence in people with dementia. There was also a reduction in injuries and serious injuries.

\section{Community: multifactorial interventions}

Four studies took place in the community. Only one [44], a multifactorial fall prevention program, found a significant reduction in falls. Although the study did not focus on people with a mental health problem they do report results of a sub-group analysis in which they found a reduction in the incidence of falls in people with depressive symptoms. A pilot RCT found a non-significant reduction in fallers and incidence of falls in older people receiving a home hazard reduction and exercise fall prevention programme [51], an uncontrolled pilot study of a fall prevention programme for people with dementia found no difference in fallers [37] and a multifactorial intervention in a geriatric outpatient clinic reported a non-significant increase in fallers and falls [32].

\section{Discussion}

\section{Summary of main results}

We found 17 RCTs and four uncontrolled studies that evaluated the impact of interventions to prevent falls in older people with mental health problems, including dementia, delirium and depression. The nature of the interventions varied considerably and involved a variety of components including physical activity and exercise, risk assessment, environmental modification, staff training, increased supervision, patient education, and sensory interventions. Evidence relating to fall reduction was inconsistent. Of the 14 studies that reported the number of fallers, eight found a reduction which was statistically significant in five, and of the 14 that reported rate or number of falls eight found some evidence of a significant reduction. However, four studies found a non-significant increase in falls in the intervention group compared to the control.

Although all the studies included participants with mental health problems only ten studies had a specific mental health focus. Studies predominantly focused on cognitive impairment, dementia and depression and there were no studies including patients with other psychiatric disorders who are likely to be on medications associated with increased risk of falls. The majority of studies were undertaken in nursing and residential homes, and there were none in mental health inpatient settings.

\section{Comparison with other literature}

Cochrane reviews looking at fall prevention interventions for older people have found evidence that multifactorial interventions are effective in preventing falls in community dwelling participants and also those in hospitals and nursing care facilities, and that multi-component exercise is effective in community settings [53,54]. We also found evidence to suggest that multifactorial interventions which included exercise can be effective in older people with cognitive impairment and depression, with four of six studies finding a reduction in falls which was significant in two $[40,48]$ although there is insufficient evidence to support physical activity or exercise alone with this population. 
Table 5 Overview of main results

Intervention/study Fallers (fell at

least once)

\section{Exercise}

Buettner $2002[28]^{2} \quad$ Reduced ${ }^{*}$; RR 0.57

95\% Cl 0.37, 0.89

Rosendahl 2008 [43] $]^{1} \quad$ No difference; RR 1.04

$95 \% \mathrm{Cl} 0.78,1.37$

\section{Social environment}

Detweiler 2005 [29] $^{2} \quad$ Falls (total number):

Reduced $^{*} \mathrm{P}=0.024$

Chenoweth $2009[27]^{2}$

\begin{tabular}{|c|c|}
\hline Shimada $2009(45)^{1}$ & Reduced $^{*} \mathrm{P}=0.012$ \\
\hline \multicolumn{2}{|c|}{ Environment/assistive technology } \\
\hline \multicolumn{2}{|l|}{ Detweiler $2009[30]^{2}$} \\
\hline \multicolumn{2}{|l|}{ Knowledge } \\
\hline Bouwen $2008[26]^{1}$ & $\begin{array}{l}\text { Reduced }^{*} ; \text { RR } 0.57 \\
(0.37,0.89)\end{array}$ \\
\hline \multicolumn{2}{|l|}{ Sensory } \\
\hline \multicolumn{2}{|l|}{ Klages $2011[36]^{2}$} \\
\hline Sakamoto $2012[44]^{1}$ & $\begin{array}{l}\text { Reduced: RR } 0.71 \\
95 \% \text { Cl 0.48,1.05 }\end{array}$ \\
\hline \multirow[t]{2}{*}{ Jensen $2003[35]^{3}$} & $\begin{array}{l}\text { Cl: No difference } \\
p=.352\end{array}$ \\
\hline & $\begin{array}{l}\text { No Cl: Reduced* } \\
p=.020\end{array}$ \\
\hline
\end{tabular}

Neyens $2006[40]^{2}$

Rapp $2008[41]^{3}$; Becker $2003^{1}$

Ray 1997 [42] ${ }^{1}$

Shaw $2003[46]^{2} \quad$ Reduced; RR 0.92 $95 \% \mathrm{Cl} 0.81,1.05$

$\begin{array}{ll}\begin{array}{l}\text { Rate/number } \\ \text { of falls }\end{array} & \begin{array}{l}\text { Fall related } \\ \text { injuries/fractures }\end{array}\end{array}$

Nursing/residential care: single
Reduced; IRR 0.82 (0.49-1.39)

Hip fractures -Reduced RR $0.1695 \%$ Cl 0.01, 3.01
Other

Quality score$$
\text { (0.49-1.39) }
$$

Fall severity - No difference $\quad 3 / 6^{4}$

$4 / 6$

DCM v control

Reduced $^{*} \mathrm{p}=0.02$

PCC v control

Increased $^{*} \mathrm{p}=0.03$

Reduced $^{*} \mathrm{p}=0.046$

$3 / 6^{4}$

Reduced $^{*} \mathrm{P}=0.05$

$2 / 6^{4}$

No difference $p=0.10$

$4 / 6$

No difference; $p=0.47$

$4 / 6$

Reduced * IRR 0.57

(95\% Cl 0.32-0.99)

\section{Nursing/residential care: multifactorial}

$$
\begin{aligned}
& \text { Injuries } \\
& \mathrm{Cl} \text { grp - No difference } \\
& \text { IRR } 0.9 \text { (95\% Cl 0.5-1.3) } \\
& \mathrm{No} \mathrm{Cl} \text { grp - No difference } \\
& \text { IRR } 0.9 \text { (95\% Cl 0.5-1.5) } \\
& \text { Hip fractures } \\
& \mathrm{Cl} \text { group Reduced* } \\
& \mathrm{P}=.006
\end{aligned}
$$

Reduced*; RR 0.64

$95 \% \mathrm{Cl} 0.43,0.96$

Cognitively impaired $^{3}$

Hip fractures ${ }^{1}$ - Increased

Reduced ${ }^{*}$; Incidence rate ratio (IRR) 0.43

(0.28-0.66)

Depression (at least one sign)

Reduced; IRR 0.74

(0.51-1.09)
Time to first fall ${ }^{3}$ (cognitively 5/6 impaired versus cognitively intact) - Increased In $^{*}$

RR 0.49 95\% Cl 0.35, 0.69

Recurrent fallers - reduced

$4 / 6$

\author{
Injurious falls \\ Reduced \\ RR 0.75 95\% Cl 0.48, 1.17
}

RR $0.8395 \%$ Cl 0.68, 1.02

Fall related A\&E admissions - 6/6 increased

RR 1.25 95\% Cl 0.91, 1.72 
Table 5 Overview of main results (Continued)

Hospital: single

Knowledge

Haines $2011[33]^{3}$

Complete intervention

vs control

Complete intervention

Injuries

Increased

Increased; $1.38(0.70,2.75)$

RR 1.84 95\% Cl 0.93, 3.62

Increased; HR 1.48 (0.86-2.53)

Materials only vs control

Materials only vs control

Decreased; OR 0.92

(0.48-1.78)

No difference; HR $0.99(0.55-1.78)$

Environment (social)

Mador 2004 [38] ${ }^{2} \quad$ Increased; RR 2.43

(0.84-7.03)

Stenvall $2007[47]^{1}$

Reduced*; RR 0.78 $(95 \% \mathrm{Cl} 0.64,0.96)$

Faes 2011 [32]

Increased RR 1.39 95\% Cl 0.66, 2.93

Mackintosh $2005[37]^{2}$

No difference $p=0.27$

Wesson $2013[51]^{2}$

Reduced; RR 0.50

(95\% Cl 0.11, 2.19)

Salminen $2009[43]^{3}$

$$
0.99 \text { (0.55-1.78) }
$$


medication review; and that those in in care settings such as care homes receive multifactorial interventions including exercise. In addition, all older people taking psychotropic medication should have this reviewed and where possible discontinued. NICE guidance also recommends that health care professionals dealing with patients at risk of falling should be educated in falls assessment and prevention. A recent audit of UK inpatient NHS settings that included mental health settings [57] found that $35 \%$ of nurses and $61 \%$ of doctors had not received training in fall prevention in the past year thus highlighting that work is needed in order to meet NICE recommendations.

\section{Limitations and quality of the evidence}

We used systematic and rigorous methods to synthesize the current evidence on the effectiveness of fall prevention interventions for older people with mental health problems. However, there are a number of methodological issues that could have a bearing on the validity of these results. Due to the scarcity of evidence relating to falls prevention in older people with mental health problems we included four uncontrolled studies which, because they are at increased risk of bias, should be interpreted cautiously. Moreover, only four of the controlled studies met all of the methodological criteria on our checklist and many appeared underpowered to detect a reduction in falls. We included seven studies that included participants with and without mental health problems and which did not report sub-group analyses for those with mental health problems. It is possible that the results from these studies are less generalizable to older people with mental health problems.

The review involved a diverse range of interventions, participants and outcomes and in light of this heterogeneity we judged meta-analysis to be inappropriate. This made direct comparisons between studies more difficult. Nevertheless, despite this, we were still able to make judgements about the strength and consistency of the findings.

\section{Difficulties undertaking research with older people with mental illness}

The lack of studies we found could reflect the additional methodological and ethical challenges which work in these settings and with these population groups entails. Researchers have highlighted the difficulties of undertaking studies with older patients with mental health problems $[41,52]$, in particular when there are issues around capacity to give informed consent [58]. However, the UK Mental Capacity Act [59] provides researchers with the means to address this, through using assent, though the process adds time and thus cost to the research. Despite this, researchers need to overcome these difficulties in order to provide practitioners with the evidence of effectiveness they need for practice.
Older people with mental health problems are likely to be older (as incidence of dementia increases with age) and frail with physical and mental health co-morbidities and this needs to be accounted for when designing interventions. The authors of one of the studies included in our review [32] suggest that their intervention failed because it was too complex and specialised and that interventions need to be tailored to the needs of frail older people, particularly when incorporating intensive physical therapy.

\section{Implications for practice and research}

Alderson and Roberts [60] argue that reviews such as this one, where the review uncovers very little evidence which practitioners can use, still need to be reported. They argue that uncovering uncertainty can help to improve the evidence base through stimulating more and better quality research.

Staff working with patients with mental health conditions need access to evidence to support their practice with this population group. Staff may be aware of the risks factors for falls, however strategies to prevent falls frequently include choosing management strategies such as restraint and observation $[19,61]$ rather than interventions which would increase balance and strength. In addition, in-patient mental health settings present unique patient-safety issues [62]. Without evidence of effectiveness of interventions staff will continue to struggle to provide care for those at risk of falls who also have a mental health issue such as dementia [19]. Further work is needed to help us to understand what interventions work in which sub groups of patients. This review therefore adds further weight to the calls for further research to help understand which elements of multifactorial interventions work, in what combination for specific groups of patients, the acceptibility of these to older people, and their cost-effectiveness $[41,52,55,56]$.

\section{Conclusions}

Despite the high number of falls experienced by older people with mental health problems, including dementia, we found very few studies reporting fall reduction interventions in mental health settings. No studies were found in mental health hospital settings. The evidence provided in this review does not provide sufficient robust evidence to produce specific guidance for practitioners providing care for older people with the range of mental health problems or in mental health settings. However, it does challenge guidance that states there is no evidence that fall prevention interventions can be effective in older people with cognitive impairment (American Geriatrics Society, British Geriatrics Society 2010). This review highlights the urgent need for further research to develop a robust evidence base to determine which interventions work, in which settings and for whom. This review suggests that the recommendations 
of UK NICE, that older people should be offered multifactorial interventions including strength and balance training, home hazard assessment, vision assessment, and medication review are applicable to older people with mental health problems [56]. Measures to improve the psychosocial care of older people with dementia also show potential. Staff working with older people at risk of falls should update their knowledge and skills regarding causes and prevention of falls.

\section{Competing interests}

We have no known conflicts of interests.

\section{Authors' contributions}

All authors were involved in protocol development, study screening and data extraction. FB, AD, CS \& CV analysed the data and FB, AD and CV wrote the paper. All authors critically reviewed the paper. All authors read and approved the final manuscript.

\section{Funding}

This work was part funded by a QR grant from the University of Hertfordshire. The funder played no role in the design, execution, analysis and interpretation of data, or writing of the study.

\section{Author details}

${ }^{1}$ Centre for Research in Primary and Community Care, University of Hertfordshire, Hatfield, Hertfordshire AL10 9AB, UK. ${ }^{2}$ Oxford Health NHS Foundation Trust, Fulbrooke Centre, Churchill Hospital, Oxford OX3 7JX, UK. ${ }^{3}$ School of Health Sciences and Social Care, Brunel University, Uxbridge UB8 $3 \mathrm{PH}, \mathrm{UK}$

Received: 13 June 2013 Accepted: 10 February 2014

Published: 19 February 2014

\section{References}

1. Healey F, Scobie S, Oliver D, Pryce A, Thomson R, Glampson B: Falls in English and Welsh hospitals: a national observational study based on retrospective analysis of 12 months of patient safety incident reports. Qual Saf Health Care 2008, 17(6):424-430.

2. National Patient Safety Agency 2010 Slips trips and falls data update NPSA. Available from www.nrls.npsa.nhs.uk.

3. Heslop K, Wynaden D, Bramanis K, Connolly C, Gee T, Griffiths R, Al Omari O: Assessing falls risk in older adult mental health patients: a Western Australian review. Int J Ment Health Nurs 2012, 21(6):567-575.

4. Finkelstein $\mathrm{E}$, Prabhu $\mathrm{M}$, Chen $\mathrm{H}$ : Increased prevalence of falls among elderly individuals with mental health and substance abuse conditions. Am J Geriatr Psychiatry 2007, 15(7):611-619.

5. Evans D, Hodgkinson B, Lambert L, Wood J: Falls risk factors in the hospital setting: a systematic review. Int J Nurs Pract 2001, 7(1):38-45.

6. Joo JH, Lenze EJ, Mulsant BH, Begley AE, Weber EM, Stack JA, Mazumdar S, Reynolds CF 3rd, Pollock BG: Risk factors for falls during treatment of late-life depression. J Clin Psychiatry 2002, 63(10):936-941.

7. de Carle AJ, Kohn R: Risk factors for falling in a psychogeriatric unit. Int $J$ Geriatr Psych 2001, 16(8):762-767.

8. Modreker MK, von Renteln-Kruse W: Medication and falls in old age. Internist 2009, 50(4):493.

9. Leipzig RM, Cumming RG, Tinetti ME: Drugs and falls in older people: a systematic review and meta-analysis: I. Psychotropic drugs. J Am Geriatr Soc 1999, 47(1):30.

10. de Carle AJ, Kohn R: Electroconvulsive therapy and falls in the elderly. J ECT 2000, 16(3):252-257.

11. McKay C, Anderson KE: How to manage falls in community dwelling older adults: a review of the evidence. Postgrad Med J 2010, 86(1015):299-306.

12. WHO: WHO global report on falls prevention in older age. Geneva Switzerland: World Health Organization; 2007. available from http://www. who.int/ageing/projects/falls_prevention_older_age/en/.

13. Oliver D, Connelly JB, Victor CR, Shaw FE, Whitehead A, Genc Y, Vanoli A Martin FC, Gosney MA: Strategies to prevent falls and fractures in hospitals and care homes and effect of cognitive impairment: systematic review and meta-analyses. BMJ 2007, 334(7584):82.

14. Jensen J, Padilla R: Effectiveness of interventions to prevent falls in people with alzheimer's disease and related dementias. Am J Occup Ther 2011, 65(5):532-540.

15. Coussement J, De Paepe L, Schwendimann R, Denhaerynck K, Dejaeger E, Milisen K: Interventions for preventing falls in acute- and chronic-care hospitals: a systematic review and meta-analysis. J Am Geriatr Soc 2008, 56(1):29-36

16. Cameron ID, Murray GR, Gillespie LD, Robertson MC, Hill Keith D, Cumming Robert G, Kerse N: Interventions for preventing falls in older people in nursing care facilities and hospitals. In Cochrane Database of Systematic Reviews. Chichester, UK: John Wiley \& Sons, Ltd; 2010.

17. Allan LM, Ballard CG, Rowan EN, Kenny RA: Incidence and prediction of falls in dementia: a prospective study in older people. PLoS One 2009, 4(5):e5521.

18. Härlein J, Dassen T, Halfens RJG, Heinze C: Fall risk factors in older people with dementia or cognitive impairment: a systematic review. J Adv Nurs 2009, 65(5):922-933.

19. Johansson I, Bachrach-Lindström M, Struksnes S, Hedelin B: Balancing integrity vs. risk of falling - nurses' experiences of caring for elderly people with dementia in nursing homes. J Res Nurs 2009, 14(1):61-73.

20. Higgins JPT, Green S: Handbook for Systematic Reviews of Interventions Version 5.1.0 [updated March 2011]. The Cochrane Collaboration, 2011. Available from www.cochrane-handbook.org.

21. Higgins J, Altman D, Sterne C: Chapter 8; Assessing the risk of bias in included studies. From the Cochrane Handbook for Systematic Reviews of Interventions. Version 5.1.0 [updated 2011]. The Cochrane Collaboration, 2011. Available from www.cochrane-handbook.org.

22. Quality Assessment Tool for Quantitative Studies: Quality assessment tool for quantitative studies. http://www.ephpp.ca/tools.html.

23. Lamb S, Becker C, Gillespie L, Smith J, Finnegan S, Potter R, Pfeiffer K, Investigators $\Pi$ : Reporting of complex interventions in clinical trials: development of a taxonomy to classify and describe fall-prevention interventions. Trials 2011, 12(1):125

24. Higgins JPT, Thompson SG: Quantifying heterogeneity in a meta-analysis Stat Med 2002, 21(11):1539-1558.

25. Becker C, Kron M, Lindemann U, Sturm E, Eichner B, Walter-Jung B, Nikolaus $\mathrm{T}$ : Effectiveness of a multifaceted intervention on falls in nursing home residents. Am Geriatr Soc 2003, 51:306-313.

26. Bouwen A, De Lepeleire J, Buntinx F: Rate of accidental falls in institutionalised older people with and without cognitive impairment halved as a result of a staff-oriented intervention. Age Ageing 2008, 37(3):306-310.

27. Chenoweth L, King MT, Jeon $Y-H$, Brodaty $H$, Stein-Parbury J, Norman R, Haas M, Luscombe G: Caring for aged dementia care resident study (CADRES) of person-centred care, dementia-care mapping, and usual care in dementia: a cluster-randomised trial. Lancet Neurol 2009, 8(4):317-325.

28. Buettner LL: Focus on caregiving. Falls prevention in dementia populations: following a trial program of recreation therapy, falls were reduced by 164 percent. Provider 2002, 28(2):41-43.

29. Detweiler MB, Kim KY, Taylor BY: Focused supervision of high-risk fall dementia patients: a simple method to reduce fall incidence and severity. Am J Alzheimers Dis Other Demen 2005, 20(2):97-104.

30. Detweiler MB, Murphy PF, Kim KY, Myers LC, Ashai A: Scheduled medications and falls in dementia patients utilizing a wander garden. Am J Alzheimers Dis Other Demen 2009, 24(4):322-332.

31. Detweiler MB, Murphy PF, Myers LC, Kim KY: Does a wander garden influence inappropriate behaviors in dementia residents? Am J Alzheimers Dis Other Demen 2008, 23:31-45.

32. Faes MC, Reelick MF, Melis RJ, Borm GF, Esselink RA, Olde Rikkert MG: Multifactorial fall prevention for pairs of frail community-dwelling older fallers and their informal caregivers: a dead end for complex interventions in the frailest fallers. J Am Med Dir Assoc 2011, 12:451-458.

33. Haines TP, Hill AM, Hill KD, McPhail S, Oliver D, Brauer S, Hoffmann T, Beer C Patient education to prevent falls among older hospital inpatients: a randomized controlled trial. Arch Intern Med 2011, 171(6):516-524.

34. Jensen J, Lundin-Olsson L, Nyberg L, Gustafson Y: Fall and injury prevention in older people living in residential care facilities: a cluster randomized trial. Ann Intern Med 2002, 136(10):733. 
35. Jensen J, Nyberg L, Gustafson Y, Lundin-Olsson L: Fall and injury prevention in residential care-effects in residents with higher and lower levels of cognition. J Am Geriatr Soc 2003, 51(5):627-635.

36. Klages K, Zecevic A, Orange JB, Hobson S: Potential of Snoezelen room multisensory stimulation to improve balance in individuals with dementia: a feasibility randomized controlled trial. Clin Rehab 2011 25(7):607-616.

37. Mackintosh SF, Sheppard LA: A pilot falls-prevention programme for older people with dementia from a predominantly Italian background. Hong Kong Physiother J 2005, 23(1):20-26.

38. Mador JE, Giles L, Whitehead C, Crotty M: A randomized controlled trial of a behavior advisory service for hospitalized older patients with confusion. Int J Geriatr Psychiatr 2004, 19(9):858-863.

39. Neyens JCL, Dijcks BPJ, Twisk J, Schols JMGA, Van Haastregt J, Van Den Heuvel WJA, De Witte LP: A multifactorial intervention for the prevention of falls in psychogeriatric nursing home patients, a randomised controlled trial (RCT). Age Ageing 2009, 38(2):194.

40. Neyens J, Dijcks B, van Haastregt J, de Witte L, van den Heuvel W, Crebolder $\mathrm{H}$, Schols J: The development of a multidisciplinary fall risk evaluation tool for demented nursing home patients in the Netherlands. BMC Public Health 2006, 6(1):74.

41. Rapp K, Lamb SE, Buchele G, Lall R, Lindemann U, Becker C: Prevention of falls in nursing homes: subgroup analyses of a randomized fall prevention trial. J Am Geriatr Soc 2008, 56(6):1092-1097.

42. Ray WA, Taylor JA, Meador KG, Thapa PB, Brown AK, Kajihara HK, Davis C, Gideon $P$, Griffin MR: A randomized trial of a consultation service to reduce falls in nursing homes. J Am Med Assoc 1997, 278(7):557-562.

43. Rosendahl E, Gustafson Y, Nordin E, Lundin-Olsson L, Nyberg L: A randomized controlled trial of fall prevention by a high-intensity functional exercise program for older people living in residential care facilities. Aging Clin Exp Res 2008, 20(1):67-75.

44. Salminen MJ, Vahlberg TJ, Salonoja MT, Aarnio PTT, Kivel S: Effect of a risk-based multifactorial fall prevention program on the incidence of falls. J Am Geriatr Soc 2009, 57(4):612-619.

45. Sakamoto Y, Ebihara S, Ebihara T, Tomita N, Toba K, Freeman S, Arai H, Kohzuki M: Fall prevention using olfactory stimulation with lavender odor in elderly nursing home residents: a randomized controlled trial. J Am Geriatr Soc 2012, 60(6):1005-1011.

46. Shimada H, Tiedemann A, Lord SR, Suzuki T: The effect of enhanced supervision on fall rates in residential aged care. Am J Physic Med Rehab 2009, 88(10):823.

47. Shaw FE, Bond J, Richardson DA, Dawson P, Steen IN, McKeith IG, Kenny RA: Multifactorial intervention after a fall in older people with cognitive impairment and dementia presenting to the accident and emergency department: randomised controlled trial. BMJ 2003, 326(7380):73.

48. Stenvall M, Olofsson B, Lundstrã $9 m$ M, Englund U, Borssen B, Svensson O, Nyberg L, Gustafson Y: A multidisciplinary, multifactorial intervention program reduces postoperative falls and injuries after femoral neck fracture. Osteoporosis Int 2007, 18(2):167-175.

49. Sjosten NM, Salonoja M, Piirtola M, Vahlberg T, Isoaho R, Hyttinen H, Aarnio P, Kivelä SL: Multifactorial fall prevention programme in home-dwelling elderly people: a randomized-controlled trial. Public Health 2007, 121:308-318.

50. Shaw FE: Risk modification of falls in cognitively impaired elderly patients attending a casualty department. In Ph.D Thesis. University of Newcastle Upon Tyne; 2001.

51. Wesson J, Clemson L, Brodaty H, Lord S, Taylor M, Gitlin L, Close J: A feasibility study and pilot randomised trial of a tailored prevention program to reduce falls in older people with mild dementia. BMC Geriatr 2013, 13(1):89.

52. Shaw FE: Falls in older people with dementia. Geriatr Aging 2003, 6(7):37-40

53. Cameron ID, Gillespie LD, Robertson MC, Murray GR, Hill KD, Cumming RG, Kerse N: Interventions for preventing falls in older people in care facilities and hospitals. Cochrane Database Syst Rev 2012(Issue 12). Art. No.: CD005465. doi: 10.1002/14651858.CD005465.pub3.

54. Gillespie LD, Robertson MC, Gillespie WJ, Sherrington C, Gates S, Clemson LM, Lamb SE: Interventions for preventing falls in older people living in the community. Cochrane Database Syst Rev 2012(Issue 9). Art. No.: CD007146. doi: 10.1002/14651858.CD007146.pub3.

55. AGS, BGS: Prevention of falls in older persons. American Geriatric Society \& British Geriatric Society. http://www.medcats.com/FALLS/frameset.htm; 2010.
56. NICE: Falls: assessment and prevention of falls in older people. June 2013. NICE clinical guideline 161 guidance.nice.org.uk/cg161. National Institute for Health and Care Excellence; 2013.

57. RCP: Report of the 2011 inpatient falls pilot audit. London: Royal College of Physicians; 2012. Commissioned by: Healthcare Quality Improvement Partnership, is available from: http://www.rcplondon.ac.uk/projects/nationalaudit-falls-and-bone-health-older-people.

58. Karlawish J: Measuring decision-making capacity in cognitively impaired individuals. Neurosignals 2008, 16(1):91-98.

59. UK Stationery Office: Mental Capacity Act. 2005. http://www.legislation.gov. uk/ukpga/2005/9/contents.

60. Alderson P, Roberts I: Should journals publish systematic reviews that find no evidence to guide practice? Examples from injury research. $B M$ 2000, 320(7231):376

61. Fonad E, Burnard P, Emami A: Shielding or caging? Healthcare staffs' views on fall risk and protection in Stockholm. Int J Older People Nurs 2008, 3(1):46-54.

62. Brickell T, Nicholls T, Procyshyn R, MCLean C, Dempster R, Lavoie J, Sahlstrom K, Tomita T, Wange E: Patient safety in mental health. Edmonton, Alberta: Candadian Patient Safety Institute and Ontario Hospital Association; 2009. available from http://www.patientsafetyinstitute.ca/ English/research/commissionedResearch/mentalHealthAndPatientSafety/ Documents/Mental Health Paper.pdf.

doi:10.1186/1472-6955-13-4

Cite this article as: Bunn et al: Preventing falls among older people with mental health problems: a systematic review. BMC Nursing 2014 13:4

\section{Submit your next manuscript to BioMed Central and take full advantage of:}

- Convenient online submission

- Thorough peer review

- No space constraints or color figure charges

- Immediate publication on acceptance

- Inclusion in PubMed, CAS, Scopus and Google Scholar

- Research which is freely available for redistribution 